02

\title{
Структура центров излучательной туннельной рекомбинации в эмульсионных микрокристаллах $\mathrm{AgBr}(\mathrm{I})$
}

\author{
(C) А.В. Тюрин, С.А. Жуков Ф \\ Научно-исследовательский институт фризики \\ Одесского национального университета им. И.И. Мечникова, \\ 65082 Одесса, Украина \\ e-mail: zhukov@onu.edu.ua
}

Поступила в редакцию 15.08.2017 г.

\begin{abstract}
Для установления структуры центров излучательной туннельной рекомбинации в эмульсионных микрокристаллах бромида серебра с примесью иода $\operatorname{AgBr}(\mathrm{I})$ и роли эмульсионной среды в их формировании исследованы зависимости спектров люминесценции от температуры в интервале от 77 до $120 \mathrm{~K}$ и кинетики нарастания максимального значения ее интенсивности на $\lambda \approx 560 \mathrm{~nm}$, а также спектр „Вспышки“ люминесценции, стимулируемой инфракрасным светом. Для исследований использовались два типа микрокристаллов $\operatorname{AgBr}_{1-x}\left(\mathrm{I}_{x}\right)(x=0.03)$ : полученные в водном растворе и на желатиновой основе. Установлено, что центрами излучательной туннельной рекомбинации в $\operatorname{AgBr}_{1-x}\left(\mathrm{I}_{x}\right)(x=0.03)$ с максимумом свечения на $\lambda \approx 560 \mathrm{~nm}$ являются донорно-акцепторные комплексы $\left\{\left(\mathrm{I}_{\mathrm{a}}^{-} \mathrm{I}_{\mathrm{a}}^{-}\right) \mathrm{Ag}_{\mathrm{i}}^{+}\right\}-$ионы иода $\mathrm{I}_{\mathrm{a}}^{-}$, расположенные в соседних анионных узлах кристаллической решетки $\operatorname{AgBr}(\mathrm{I})$, рядом с которыми находится межузельный ион серебра $\mathrm{Ag}_{\mathrm{i}}^{+}$. С повышением температуры центры $\left\{\left(\mathrm{I}_{\mathrm{a}}^{-} \mathrm{I}_{\mathrm{a}}^{-}\right) \mathrm{Ag}_{\mathrm{i}}^{+}\right\}$подвергаются структурному преобразованию в центры $\left\{\left(\mathrm{I}_{\mathrm{a}}^{-} \mathrm{I}_{\mathrm{a}}^{-}\right) \mathrm{Ag}_{\mathrm{i} n}^{+}\right\}$, где $n=2,3 \ldots$. При этом центры $\left\{\left(\mathrm{I}_{\mathrm{a}}^{-} \mathrm{I}_{\mathrm{a}}^{-}\right) \mathrm{Ag}_{\mathrm{i} n}^{+}\right\}, n=2$, после захвата ими электрона и дырки также обеспечивают туннельную рекомбинацию с максимумом свечения на $\lambda \approx 720 \mathrm{~nm}$. Влияние эмульсионной среды сводится к тому, что желатина, взаимодействуя с поверхностными центрами локализации электронов - межузельными ионами серебра $\mathrm{Ag}_{\mathrm{in}}^{+}, n=1,2$, образует с ними комплексы $\left\{\mathrm{Ag}_{\mathrm{in}}^{0} \mathrm{G}^{+}\right\}, n=1,2$. Последние являются более глубокими ловушками для электронов с малым сечением захвата по сравнению с центрами $\mathrm{Ag}_{\mathrm{in}}^{+}, n=1,2$, и проявляются в том, что кинетика нарастания люминесценции в $\operatorname{AgBr}(\mathrm{I})$ до стационарного уровня на $\lambda \approx 560 \mathrm{~nm}$ характеризуется наличием „вспышечного разгорания“. При этом „вспышка“ люминесценции, стимулируемая ИК светом, за которую ответственны центры локализации электронов $\mathrm{Ag}_{\mathrm{in}}^{+}, n=1,2$, отсутствует. Предполагается, что электроны, локализованные на комплексах $\left\{\mathrm{Ag}_{\mathrm{in}}^{0} \mathrm{G}^{+}\right\}, n=2$, сохраняют способность к излучательной туннельной рекомбинации с дырками, локализованными на парных иодных центрах, с максимумом свечения на $\lambda \approx 750 \mathrm{~nm}$.
\end{abstract}

DOI: $10.21883 /$ OS.2018.02.45520.182-17

\section{Введение}

В эмульсионных микрокристаллах бромида серебра с примесью иода (ЭМК $\mathrm{AgBr}(\mathrm{I}))$, содержащих на поверхности желатину и другие поверхностно-активные вещества $[1,2]$, свечение может возникать при излучательной туннельной рекомбинации локализованных электрона и дырки по механизму, аналогичному модели ВильямсаПренера [3]. Данная схема реализуется следующим образом: в запрещенной зоне вблизи потолка валентной зоны располагается уровень локализации дырок $A$, а ниже дна зоны проводимости располагается уровень локализации электронов Д. После того, как произошли оба захвата, дырки на центр $A$ и электрона на центр Д, происходит переход электрона с уровня Д на уровень $A$, который сопровождается испусканием кванта света.

В рассматриваемом случае в качестве $A$ выступает парный иодный центр $\left(\mathrm{I}_{a}^{-} \mathrm{I}_{a}^{-}\right)-$ионы иода $\mathrm{I}_{a}^{-}$, pacположенные в соседних анионных узлах кристаллической решетки ЭМК $\mathrm{AgBr}(\mathrm{I})$. Предполагается также, что при локализации дырки парным иодным центром воз- никает молекулярное образование $\left(\mathrm{I}_{2}^{-}\right)_{\text {aа }}$, аналогичное $V_{k}$-центру в ЩГК [4]:

$$
\left(\mathrm{I}_{\mathrm{a}}^{-} \mathrm{I}_{\mathrm{a}}^{-}\right)+p \rightarrow\left(\mathrm{I}_{2}^{-}\right)_{\mathrm{aa}},
$$

где $p$ - дырка, мигрирующая в валентной зоне.

Что касается центра Д, то относительно его природы нет достоверных данных, которые однозначно бы устанавливали природу этого центра. На сегодняшний день наиболее убедительным считается предположение, что данным центром локализации электронов является поверхность ЭМК $\mathrm{AgBr}(\mathrm{I})$, находящаяся в контакте с желатиной [5]. При взаимодействии желатины с поверхностью ЭМК $\mathrm{AgBr}(\mathrm{I})$ происходит хемосорбция желатины [6,7]. Макромолекулы желатины связываются поверхностными ионами серебра с образованием серебряно-желатиновых комплексов [8]. Возникновение серебряно-желатиновых комплексов сопровождается вытягиванием электронов из объема ЭМК $\mathrm{AgBr}(\mathrm{I})$ к поверхности и локализацией их на дефектах приповерхностного слоя $[2,8]$. Поэтому, по мнению авторов работы $[8]$, возникновение зеленого свечения парных иодных центров у распределенных в желатине 


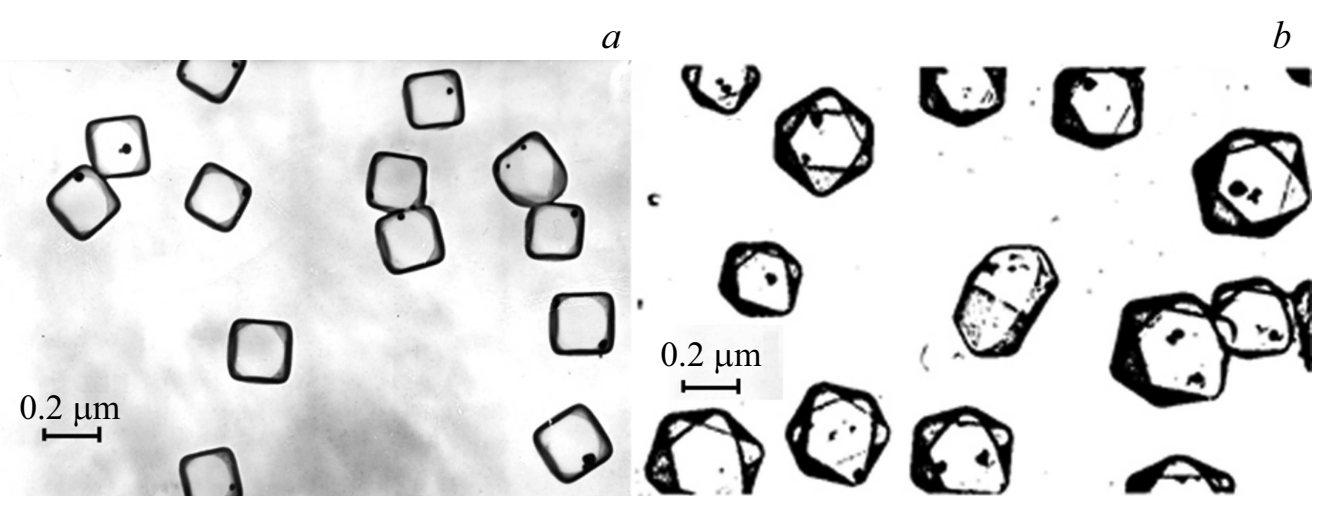

Рис. 1. Электронно-микроскопические фотографии угольно-платиновых реплик кубических $(a)$ и октаэдрических $(b)$ ЭМК $\operatorname{AgBr}_{1-x}\left(\mathrm{I}_{x}\right)(x=0.03)$.

ЭМК $\operatorname{AgBr}(\mathrm{I})$, является рекомбинация дырок, локализованных на парных иодных центрах, с электронами, локализованными на поверхности ЭМК $\mathrm{AgBr}(\mathrm{I})$. Данное предположение, на наш взгляд, не получило достаточного теоретического и экспериментального обоснования, а многие имеющиеся экспериментальные результаты, например по температурному тушению зеленого свечения ЭМК $\operatorname{AgBr}(\mathrm{I})$ и влиянию эмульсионной среды на ее кинетику, не находят своего объяснения в рамках данной модели [8]. Это и послужило мотивом для нашей работы, которая посвящена выяснению указанных особенностей структуры наноразмерных центров, ответственных за излучательный туннельный механизм зеленой люминесценции ЭМК $\operatorname{AgBr}(\mathrm{I})$, и роли эмульсионной среды в их формировании.

\section{1. Постановка задачи и методы экспериментального исследования}

Для установления структуры центров излучательной туннельной рекомбинации в ЭМК $\operatorname{AgBr}(\mathrm{I})$ и роли эмульсионной среды в их формировании в работе исследованы спектры люминесценции в зависимости от температуры в интервале от 77 до $120 \mathrm{~K}$ и кинетики изменения максимального значения ее интенсивности на $\lambda \approx 560 \mathrm{~nm}$, а также спектр „вспышки“ люминесценции, стимулируемой ИК светом. Для исследований использовались два типа ЭМК $\operatorname{AgBr}(\mathrm{I})$ : полученные в водном растворе и на желатиновой основе методом контролируемой двухструйной эмульсификации [3] по реакции двойного обмена:

$$
\mathrm{AgNO}_{3}+[\mathrm{KBr}(97 \%)+\mathrm{KI}(3 \%)] \rightarrow \mathrm{AgBr}(\mathrm{I})+\mathrm{KNO}_{3}
$$

Контроль огранки и размеров синтезированных ЭМК $\mathrm{AgBr}(\mathrm{I})$ осуществлялся с помощью электронного микроскопа типа УМВ-100К при наблюдении их угольных реплик, оттененных платиной. Типичные электронно-микроскопические фотографии получаемых ЭМК $\operatorname{AgBr}_{1-x}\left(\mathrm{I}_{x}\right)(x=0.03)$ в желатине показаны на рис. 1. В последующем изложении ЭМК $\operatorname{AgBr}_{1-x}\left(\mathrm{I}_{x}\right)$ $(x=0.03)$ будут обознаться ЭМК $\operatorname{AgBr}(\mathrm{I})$ без указания концентрации введенного йода. По электронномикроскопическим исследованиям средний размер ЭМК $\operatorname{AgBr}(\mathrm{I})$ в эмульсиях составлял $0.24 \mu \mathrm{m}$ (рис. 1).

Исследования спектров люминесценции ЭМК $\operatorname{AgBr}(\mathrm{I})$ и кинетики изменения максимального значения ее интенсивности на $\lambda \approx 560 \mathrm{~nm}$, а также спектра „вспышки“ люминесценции, стимулируемой ИК светом в температурном интервале от 77 до $120 \mathrm{~K}$, проводились нами на переменном токе при возбуждении П-импульсами с частотой следования импульсов $800 \mathrm{~Hz}$ светом с $\lambda \approx 460 \mathrm{~nm}$ по методике и на установке, описанных в [9]. При этом регистрируется лишь фосфоресценция центров свечения с временами релаксации $\tau>2.0 \mathrm{~ms}$, именно эти релаксационные процессы фотовозбуждения в данном случае нас и интересуют.

Измерение спектра „вспышки“ свечения ЭМК $\mathrm{AgBr}(\mathrm{I})$ осуществлялось следующим образом: образец возбуждался светом ртутной лампы $\lambda=365 \mathrm{~nm}$ в течение $1 \mathrm{~min}$. Затем через темновой интервал $30 \mathrm{~s}$, в течение которого послесвечение практически отсутствовало, включалось неразложенное ИК излучение с длинами волн $\lambda \geq 1000 \mathrm{~nm}$ (фильтр ИКС-3 или германиевый светофильтр толщиной $1.5 \mathrm{~mm})$. Регистрация „вспышки“ свечения на заданной длине волны при этом осуществлялась катодным осциллографом C1-19. Влияние ИК подсветки на заданной длине волны оценивалось максимальным изменением интенсивности люминесценции во „вспышке“ $I_{\text {flash }}$ при заданном темновом интервале: $I_{\text {flash }}=I_{\max }-I_{0}$, где $I_{\max }-$ максимальное значение интенсивности свечения во „вспышке“, $I_{0}$ интенсивность послесвечения на данной длине волны в заданном темновом интервале. В основном воздействие ИК подсветки осуществлялось при условии, когда $I_{0} \approx 0$. 

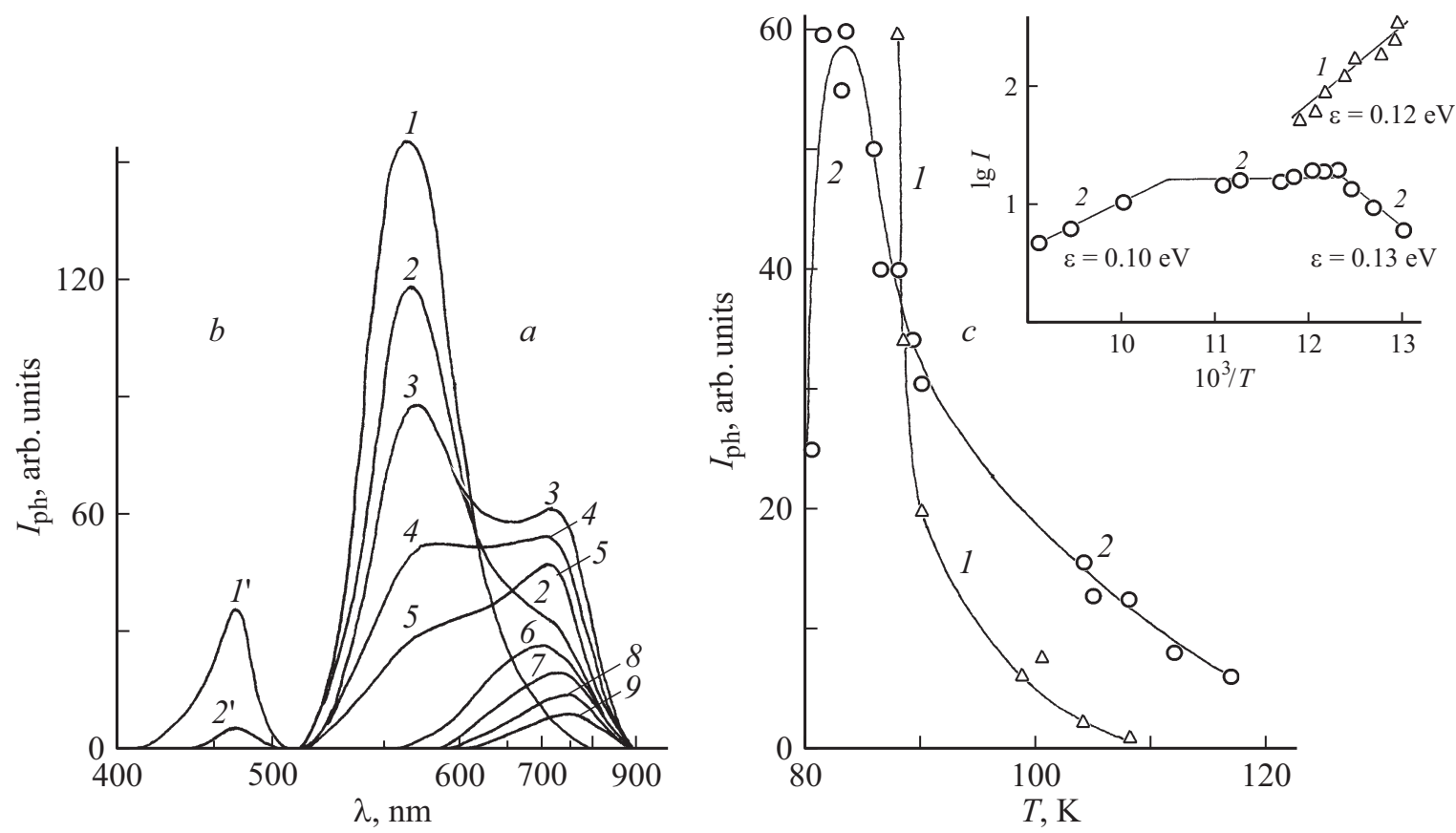

Рис. 2. (a) Спектры свечения ЭМК $\operatorname{AgBr}(\mathrm{I})$, полученных в водном растворе при возбуждении светом с $\lambda \approx 460 \mathrm{~nm}$ при температурах 81 (1), 86 (2), 88 (3), 88.5 (4), 90 (5), 104 (6), 108 (7), $112(8), 117 \mathrm{~K}(9)$. (b) Спектры возбуждения свечения ЭМК $\operatorname{AgBr}(\mathrm{I})$ на $\lambda \approx 570\left(2^{\prime}\right)$ и $720 \mathrm{~nm}\left(1^{\prime}\right)$ при разных температурах $96\left(1^{\prime}\right), 104 \mathrm{~K}\left(2^{\prime}\right)$. (c) Зависимость интенсивности свечения ЭМК $\mathrm{AgBr}(\mathrm{I})$ от температуры на $\lambda_{\max }=560(1), 720 \mathrm{~nm}(2)$ при возбуждении светом с $\lambda \approx 460 \mathrm{~nm}$; на вставке - логарифмическая зависимость интенсивности свечения на этих же длинах волн от обратной температуры.

\section{Экспериментальные результаты}

На рис. 2 представлены результаты измерения спектров люминесценции ЭМК $\operatorname{AgBr}(\mathrm{I})$, полученных в водном растворе при различных температурах в интервале от 77 до $120 \mathrm{~K}$.

Как показали исследования, спектры люминесценции ЭМК $\operatorname{AgBr}(\mathrm{I})$ в температурном интервале $77 \mathrm{~K}<T<88 \mathrm{~K}$ характеризуются широкой полосой зеленого свечения с максимумом на $\lambda_{\max } \approx 560 \mathrm{~nm}$ (рис. 2, $a$, кривые $1-3$ ). В области температур $T>88 \mathrm{~K}$ люминесценция ЭМК $\operatorname{AgBr}(\mathrm{I})$ с $\lambda_{\max } \approx 560 \mathrm{~nm}$ испытывает резкий спад интенсивности (рис. 2,c, кривая 1), т.е. температурное „тушение“ зеленого свечения. Температурное „тушение“ зеленого свечения происходит с энергией активации $\varepsilon \approx 0.12 \mathrm{eV}$ (рис. 2, $c$, вставка, кривая 1 ), совпадающей с энергией перемещения межузельного иона $\mathrm{Ag}_{\mathrm{i}}^{+}$серебра (здесь индекс і указывает на межузельное расположение иона в кристаллической решетке) в ЭМК $\mathrm{AgBr}(\mathrm{I})$, равной 0.10-0.16 eV [10].

В процессе температурного „тушения“ зеленого свечения наблюдается возникновение свечения с максимумом на $\lambda_{\max } \approx 720 \mathrm{~nm}$ (рис. $2, a$, кривые $3-9$ ), который с повышением температуры имеет тенденцию смещаться в длинноволновую часть спектра.

Исследования показали также, что возрастание интенсивности длинноволнового свечения с $\lambda_{\max } \approx 720 \mathrm{~nm}$ в области температур $80 \mathrm{~K}<T<90 \mathrm{~K}$ и температур- ное „тушение“ этого свечения в области температур $T>95 \mathrm{~K}$ (рис. 2, c, вставка, кривая 2) происходят с термическими энергиями активации такими же, как и для температурного „тушения“ зеленой полосы свечения (рис. 2, c, вставка, кривая 1), и укладывающимися в интервал энергии перемешения межузельного иона серебра $\mathrm{Ag}_{\mathrm{i}}^{+}$в ЭМК $\mathrm{AgBr}(\mathrm{I}) \varepsilon=0.10-0.16 \mathrm{eV}$.

Результаты измерения спектров люминесценции ЭМК $\operatorname{AgBr}(\mathrm{I})$, полученных на желатиновой основе, отличаются лишь тем, что для ЭМК $\operatorname{AgBr}(\mathrm{I})$, распределенных в желатине, возникающее длинноволновое свечение при температурном „тушении“ зеленого свечения выражено не так ярко, и максимум свечения наблюдается на $\lambda_{\max } \approx 750 \mathrm{~nm}$, а не $720 \mathrm{~nm}$, как для ЭМК $\operatorname{AgBr}(\mathrm{I})$, полученных в водном растворе. Для сравнения на рис. 3 представлены результаты измерения спектров люминесценции и возбуждения при температурах в области температурного „тушения“ зеленой полосы свечения для ЭМК $\operatorname{AgBr}(\mathrm{I})$, полученных в водном растворе и на желатиновой основе.

Следует отметить, что спектры возбуждения полос люминесценции с $\lambda_{\max } \approx 560,720 \mathrm{~nm}$ (рис. $2, b$, кривые $1^{\prime}$ и $2^{\prime}$ ) и $\lambda_{\max } \approx 750 \mathrm{~nm}$ (рис. $3, b$, кривая 3') одинаковы независимо от температуры измерения.

Существенные различия для ЭМК $\operatorname{AgBr}(\mathrm{I})$, полученных в водном растворе и на желатиновой основе, наблюдаются в поведении кинетики нарастания люминесценции на $\lambda \approx 560 \mathrm{~nm}$ до стационарного уровня и в 


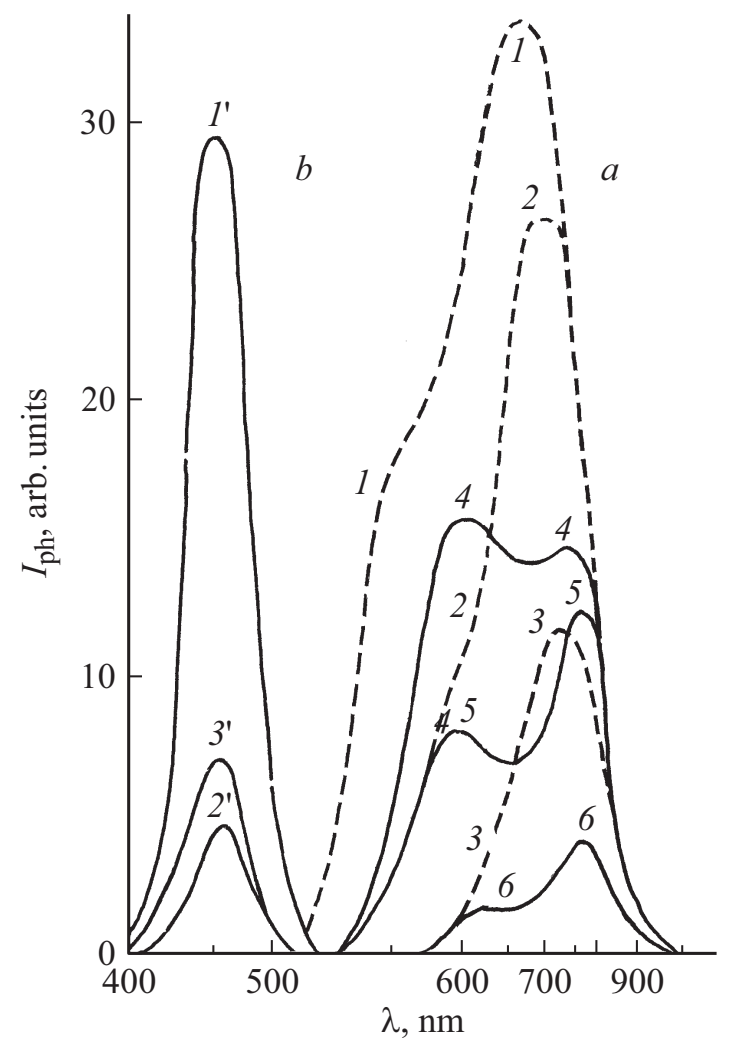

Pис. 3. (a) Спектры свечения ЭМК $\operatorname{AgBr}(\mathrm{I})$, полученных в водном растворе (1-3) и на желатиновой основе (4-6) при возбуждении светом с $\lambda \approx 460 \mathrm{~nm}$ при температурах $97(1,4), 104(2,5), 112 \mathrm{~K}(3,6)$. (b) Спектры возбуждения свечения ЭМК $\operatorname{AgBr}(\mathrm{I})$, полученных в водном растворе $\left(1,2^{\prime}\right)$ и на желатиновой основе $\left(3^{\prime}\right)$ на $\lambda \approx 560 \mathrm{~nm}$ при $96 \mathrm{~K}\left(2^{\prime}\right)$, $\lambda \approx 720 \mathrm{~nm}$ при $104 \mathrm{~K}\left(1^{\prime}\right), \lambda \approx 750 \mathrm{~nm}$ при $110 \mathrm{~K}\left(3^{\prime}\right)$. спектре „вспышки“ люминесценции, стимулируемой ИК светом. Если для ЭМК $\operatorname{AgBr}(\mathrm{I})$, полученных в водном растворе, нарастание люминесценции до стационарного уровня происходит монотонно (рис. 4, $a$, кривая 1) и наблюдается „вспышка“ люминесценции, стимулируемая ИК светом, с максимумами на $\lambda_{\max } \approx 560$ и $720 \mathrm{~nm}$ (рис. $4, b$, кривая 1 ), то в желатиновой среде нарастание люминесценции до стационарного уровня характеризуется наличием „вспышечного разгорания“ (рис. 4, $a$, кривая 3), а „вспышка“ люминесценции, стимулируемая ИК светом, во всем измеряемом спектральном диапазоне отсутствует (рис. $4, b$, кривая 2 ).

\section{Обсуждение результатов}

Тот факт, что температурное „тушение свечения в ЭМК $\mathrm{AgBr}(\mathrm{I})$ сопровождается появлением новой полосы люминесценции с максимумом свечения на $\lambda_{\max } \approx 720 \mathrm{~nm}$ для ЭМК $\operatorname{AgBr}(\mathrm{I})$, полученных в водном растворе, и $\lambda_{\max } \approx 750 \mathrm{~nm}$ для ЭМК $\operatorname{AgBr}(\mathrm{I})$, полученных на желатиновой основе, свидетельствует, на наш взгляд, о том, что центры, ответственные за зеленое свечение в ЭМК $\operatorname{AgBr}(\mathrm{I})$, в процессе температурного „тушения“ претерпевают структурное преобразование, не зависящее от связующей среды, и при этом вновь образующиеся центры сохраняют способность к туннельной рекомбинации между возбужденными состояниями с испусканием кванта с $\lambda=720-750 \mathrm{~nm}$. Ответственными за данное преобразование являются подвижные межузельные ионы серебра $\mathrm{Ag}_{\mathrm{i}}^{+}$.

Все эти факторы позволяют высказать следующее предположение относительно особенностей структуры
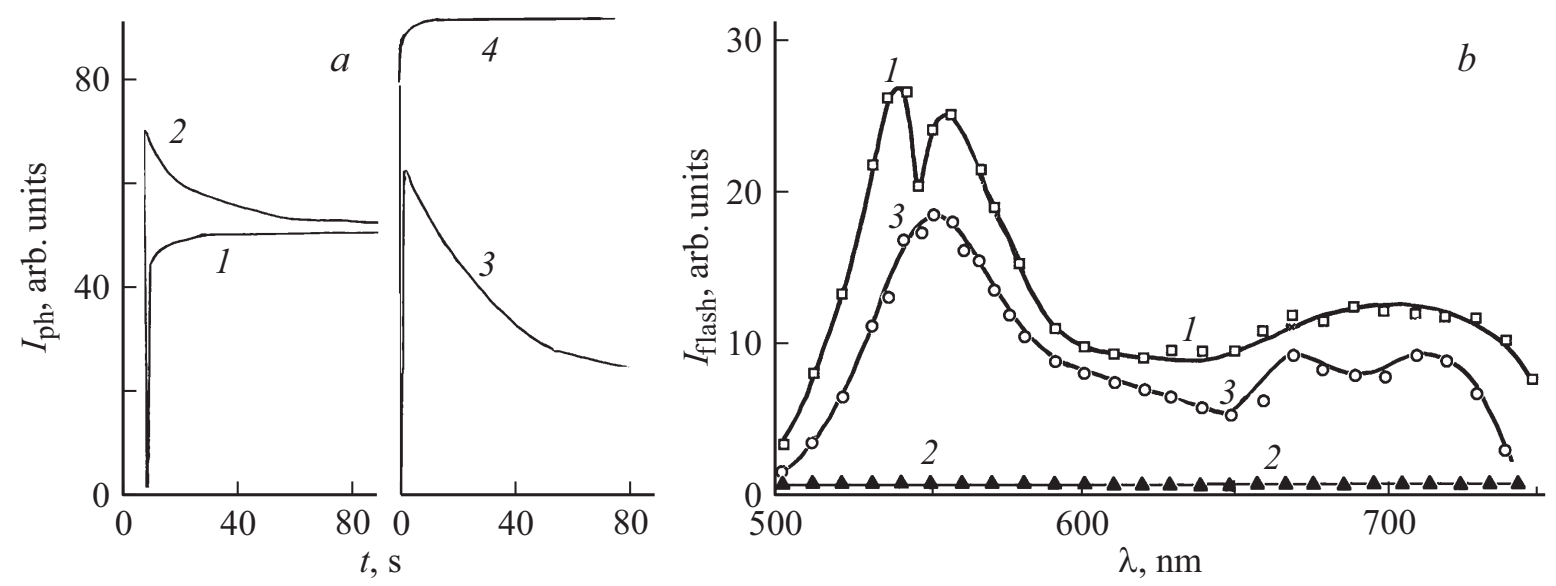

Рис. 4. (a) Кинетики нарастания интенсивности люминесценции ЭМК $\operatorname{AgBr}(\mathrm{I})$ на $\lambda \approx 560$ nm при $77 \mathrm{~K}$ под действием возбуждающего света с $\lambda=460 \mathrm{~nm}$ для полученных в водном растворе $(1)$, в водном растворе с дополнительно введенной желатиной (5мол.\%) (2), в желатине (3), в желатине при введении фенилмеркаптотетразола (10 $\left.{ }^{-3} \mathrm{~mol} / \mathrm{mol} \mathrm{AgBr}\right)(4)$. (b) Спектр „вспышки“ $I_{\text {flash }}=I_{\max }-I_{0}$ люминесценции, стимулируемой ИК светом при $77 \mathrm{~K}$ для $Э \mathrm{MK} A g B r(\mathrm{I})$, полученных в водном растворе (1), в водном растворе с дополнительно введенной желатиной (5mol.\%) (2), в желатине при введении фенилмеркаптотетразола $\left(10^{-3} \mathrm{~mol} / \mathrm{mol} \mathrm{AgBr}\right)(3)$. 
центров, ответственных за зеленое свечение в ЭМК $\operatorname{AgBr}(\mathrm{I})$ с $\lambda_{\max } \approx 560 \mathrm{~nm}$ по туннельному механизму, и их преобразования с изменением температуры. Центры зеленого свечения по туннельному механизму в ЭМК $\operatorname{AgBr}(\mathrm{I})$ состоят из парного иодного центра $\left(\mathrm{I}_{\mathrm{a}}^{-} \mathrm{I}_{\mathrm{a}}^{-}\right)$и расположенного рядом с ним межузельного иона серебpa $\mathrm{Ag}_{\mathrm{i}}^{+}$, образуя единый донорно-акцепторный комплекс $\left\{\left(\mathrm{I}_{\mathrm{a}}^{-} \mathrm{I}_{\mathrm{a}}^{-}\right) \mathrm{Ag}_{\mathrm{i}}^{+}\right\}$.

Появление зеленого свечения в данном случае с учетом реакции (1) можно описать следующей схемой:

$$
\begin{aligned}
\left\{\left(\mathrm{I}_{\mathrm{a}}^{-} \mathrm{I}_{\mathrm{a}}^{-}\right)\right. & \left.\mathrm{Ag}_{\mathrm{i}}^{+}\right\}+p \rightarrow\left\{\left(\mathrm{I}_{2}^{-}\right)_{\mathrm{aa}} \mathrm{Ag}_{\mathrm{i}}^{+}\right\}+\mathrm{e} \\
& \rightarrow\left\{\left(\mathrm{I}_{2}^{-}\right)_{\mathrm{aa}} \mathrm{Ag}_{\mathrm{i}}^{0}\right\} \rightarrow\left\{\left(\mathrm{I}_{\mathrm{a}}^{-} \mathrm{I}_{\mathrm{a}}^{-}\right) \mathrm{Ag}_{\mathrm{i}}^{+}\right\}+h v_{\text {lum }} .
\end{aligned}
$$

Таким образом, интенсивность зеленой люминесценции ЭМК $\operatorname{AgBr}(\mathrm{I})$ определяется туннельными переходами в центрах $\left\{\left(\mathrm{I}_{2}^{-}\right)_{\mathrm{aa}} \mathrm{Ag}_{\mathrm{i}}^{0}\right\}$, а ее „тушение“ - межузельными ионами серебра $\mathrm{Ag}_{i}^{+}$и позволяет описать ее следующей последовательностью реакций:

$$
\begin{aligned}
& \left\{\left(\mathrm{I}_{2}^{-}\right)_{\mathrm{aa}} \mathrm{Ag}_{\mathrm{i}}^{0}\right\}+\mathrm{Ag}_{\mathrm{i}}^{+} \rightarrow\left\{\left(\mathrm{I}_{2}^{-}\right)_{\mathrm{aa}} \mathrm{Ag}_{\mathrm{i} 2}^{+}\right\}+\mathrm{e} \\
& \quad \rightarrow\left\{\left(\mathrm{I}_{2}^{-}\right)_{\mathrm{aa}} \mathrm{Ag}_{\mathrm{i} 2}^{0}\right\}+\mathrm{Ag}_{\mathrm{i}}^{+} \rightarrow\left\{\left(\mathrm{I}_{2}^{-}\right)_{\mathrm{aa}} \mathrm{Ag}_{\mathrm{i} 3}^{+}\right\}+\mathrm{e} \rightarrow \ldots
\end{aligned}
$$

Образование в процессе температурного „тушения“ центров молекулярно-кластерной дисперсности $\left\{\left(\mathrm{I}_{2}^{-}\right)_{\mathrm{aa}} \mathrm{Ag}_{\mathrm{i} n}^{+}\right\}, n=2$, также сопровождается появлением туннельной люминесценции с максимумом свечения на $\lambda_{\max } \approx 720 \mathrm{~nm}$ по схеме

$$
\begin{aligned}
\left\{\left(\mathrm{I}_{\mathrm{a}}^{-} \mathrm{I}_{\mathrm{a}}^{-}\right) \mathrm{Ag}_{\mathrm{i} n}^{+}\right\}+p & \left.\rightarrow\left\{\left(\mathrm{I}_{2}^{-}\right)\right)_{\mathrm{aa}} \mathrm{Ag}_{\mathrm{i} n}^{+}\right\}+\mathrm{e} \\
\rightarrow\left\{\left(\mathrm{I}_{2}^{-}\right){ }_{\mathrm{aa}} \mathrm{Ag}_{\mathrm{i} n}^{0}\right\} & \rightarrow\left\{\left(\mathrm{I}_{\mathrm{a}}^{-} \mathrm{I}_{\mathrm{a}}^{-}\right) \mathrm{Ag}_{\mathrm{i} n}^{+}\right\}+h v_{\text {lum }} .
\end{aligned}
$$

Дополнительным экспериментальным подтверждением нашего предположения о том, что ответственными за полосу свечения с $\lambda_{\max } \approx 720 \mathrm{~nm}$ в ЭМК $\operatorname{AgBr}(\mathrm{I})$ являются центры $\left\{\left(\mathrm{I}_{2}^{-}\right)_{\mathrm{aa}} \mathrm{Ag}_{\mathrm{i} n}^{0}\right\}, n=2$, может служить также следующий факт. При увеличении концентрации ионов серебра в ЭМК $\operatorname{AgBr}(\mathrm{I})$ путем снижения $\mathrm{pAg}$ при их синтезе, в спектре люминесценции таких ЭМК уже при $T \approx 77 \mathrm{~K}$ без предварительного цикла температурного „тушения“ регистрировалась полоса люминесценции с $\lambda_{\max } \approx 720 \mathrm{~nm}$, в которой действием ИК света стимулируется „вспышка“".

Специфичность адсорбции молекул желатины на поверхности ЭМК $\operatorname{AgBr}(\mathrm{I})$, по нашему мнению, сводится к восстановлению поверхностных центров локализации электронов, межузельных ионов серебра $\mathrm{Ag}_{\mathrm{i}}^{+}$(либо межузельных молекул серебра $\left.\mathrm{Ag}_{\mathrm{i} 2}^{+}\right)$, до атома $\mathrm{Ag}_{\mathrm{i}}^{0}$ (либо до молекулы $\mathrm{Ag}_{\mathrm{i} 2}^{0}$ ). Проявляются данные центры в отсутствии желатины при ИК подсветке, обеспечивая „Вспышку“ люминесценции (рис. 4, $b$, кривая 1) с максимумами на $\lambda_{\max } \approx 560$ и $720 \mathrm{~nm}$. Образующиеся центры $\left\{\mathrm{Ag}_{\mathrm{i} n}^{0} \mathrm{G}^{+}\right\}$, где $n=1,2$, а $\mathrm{G}^{+}$- молекула желатины, являются более глубокими ловушками для электронов с малым сечением захвата по сравнению с поверхностными центрами локализации электронов $\left\{\mathrm{Ag}_{\mathrm{i} n}^{+}\right\}, n=1,2$, и проявляются в том, что кинетика нарастания люминесценции на $\lambda \approx 560 \mathrm{~nm}$ до стационарного уровня характеризуется наличием „вспышечного разгорания“ (рис. 4, a, кривая 3), а „вспышка“ люминесценции, стимулируемая ИК светом, отсутствует (рис. 4, $b$, кривая 2). Спадание интенсивности люминесценции ЭМК $\operatorname{AgBr}(\mathrm{I})$ на $\lambda \approx 560 \mathrm{~nm}$ при взаимодействии их с желатиной (,усталость“ люминесценции) наблюдалось и в [1113]. В пользу данного предположения свидетельствуют также появление „вспышечного разгорания“ для ЭМК $\operatorname{AgBr}(\mathrm{I})$, полученных в водном растворе с дополнительно введенной желатиной (рис. 4, a, кривая 2), а также отсутствие „вспышечного разгорания“ (рис. 4, $a$, кривая 4) и появление „вспышки“ люминесценции, стимулируемой ИК светом, для желатиновой эмульсии при введении в нее фенилмеркаптотетразола (рис. 4,b, кривая 3). Известно [14], что при введении в эмульсию фенилмеркаптотетразола желатина с поверхностными межузельными ионами серебра не взаимодействует, и соответственно центры $\left(\mathrm{Ag}_{\mathrm{i} n}^{0} \mathrm{G}^{+}\right)$не образуются.

Наконец, поскольку для ЭМК $\operatorname{AgBr}(\mathrm{I})$, распределенных в желатине, возникающее длинноволновое свечение при температурном „тушении“ зеленого свечения наблюдается на $\lambda_{\max } \approx 750 \mathrm{~nm}$, а не на $720 \mathrm{~nm}$, как в ЭМК $\operatorname{AgBr}(\mathrm{I})$, полученных в водном раствоpe, естественно предположить, что молекулы желатины взаимодействуют и с расположенными на поверхности ЭМК $\operatorname{AgBr}(\mathrm{I})$ центрами туннельной люминесценции $\left\{\left(\mathrm{I}_{\mathrm{a}}^{-} \mathrm{I}_{\mathrm{a}}^{-}\right) \mathrm{Ag}_{\mathrm{i} n}^{+}\right\}, n=2$, с максимумом свечения на $\lambda_{\max } \approx 720 \mathrm{~nm}$, формируя при этом донорноакцепторные комплексы $\left\{\left(\mathrm{I}_{\mathrm{a}}^{-} \mathrm{I}_{\mathrm{a}}^{-}\right) \mathrm{Ag}_{\mathrm{i} n}^{+} \mathrm{G}^{0}\right\}, \quad n=2$. При этом локализованные электроны и дырки на комплекce $\left\{\left(\mathrm{I}_{\mathrm{a}}^{-} \mathrm{I}_{\mathrm{a}}^{-}\right) \mathrm{Ag}_{\mathrm{in}}^{+} \mathrm{G}_{0}\right\}, \quad n=2, \quad$ сохраняют способность к туннельной рекомбинации с максимумом свечения на $\lambda_{\max } \approx 750 \mathrm{~nm}$.

\section{Выводы}

На основе экспериментальных результатов высказано предположение, что возникновение зеленого свечения ЭМК $\operatorname{AgBr}(\mathrm{I})$ с $\lambda_{\max } \approx 560 \mathrm{~nm}$ по туннельному механизму вызвано рекомбинацией дырок, локализованных на парных иодных центрах $\left(\mathrm{I}_{\mathrm{a}}^{-} \mathrm{I}_{\mathrm{a}}^{-}\right)$, с электронами, локализованными не на поверхности ЭМК $\operatorname{AgBr}(\mathrm{I})$, а на межузельных ионах серебра $\mathrm{Ag}_{\mathrm{i}}^{+}$, расположенных рядом с парным иодным центром. В процессе освещения и изменения температуры межузельные ионы серебра $\mathrm{Ag}_{\mathrm{i}}^{+}$, расположенные рядом с парным иодным центром, способны формировать центры молекулярнокластерной дисперсности $\mathrm{Ag}_{\mathrm{i} n}^{+}, n=2,3, \ldots$ Электроны, локализованные на центрах $\mathrm{Ag}_{\mathrm{i} n}^{+}, n=2$, сохраняют способность к туннельной рекомбинации с дырками, локализованными на парных иодных центрах со свечением $\lambda_{\text {max }} \approx 720 \mathrm{~nm}$.

Адсорбция молекул желатины на поверхности ЭМК $\operatorname{AgBr}(\mathrm{I})$ приводит к восстановлению поверхностных 
межузельных серебряных атомно-молекулярных центров $\mathrm{Ag}_{\mathrm{i} n}^{+}, \quad n=1,2, \quad$ с образованием комплексов $\left(\mathrm{Ag}_{\mathrm{i} n}^{0} \mathrm{G}^{+}\right), n=1,2$. Центры $\left(\mathrm{Ag}_{\mathrm{i} n}^{0} \mathrm{G}^{+}\right), n=1,2$, являются более глубокими ловушками для электронов с малым сечением захвата по сравнению с центрами $\mathrm{Ag}_{\mathrm{i} n}^{+}, n=1,2$, и проявляются в том, что кинетика нарастания люминесценции в ЭМК $\operatorname{AgBr}(\mathrm{I})$ до стационарного уровня на $\lambda \approx 560 \mathrm{~nm}$ характеризуется наличием „вспышечного разгорания“, а „вспышка“ люминесценции во всем измеряемом спектральном диапазоне, стимулируемая ИК светом, отсутствует. Электроны, локализованные на центрах $\left(\mathrm{Ag}_{\mathrm{i} n}^{0} \mathrm{G}^{+}\right), n=2$, сохраняют способность к туннельной рекомбинации с дырками, локализованными на парных иодных центрах, со свечением с $\lambda_{\max } \approx 750 \mathrm{~nm}$.

\section{Список литературы}

[1] Белоус В.М., Голуб С.И., Орловская Н.А. // Журнал научн. и прикл. фотогр. и кинематогр. 1969. Т. 14. № 1. С. 39.

[2] Белоус В.М., Мельничук Л.П., Орловская Н.А., Чибисов К.В. // ДАН СССР. 1970. Т. 193. № 5. С. 1086.

[3] Миз К., Джсеймс T. Теория фотографического процесса. Л.: Химия, 1973. 572 с.

[4] Белоус В.М., Толстобров В.И., Чурашов В.П., Суворuн В.В. // Журнал научн. и прикл. фотогр. и кинематогр. 1977. T. 22. № 5. C. 390.

[5] Зимкин Е.А., Ключевич Р.Ф. // Успехи научной фотографии. 1972. Т. 16. С. 136.

[6] Зимкин Е.А., Ключевич Р.Ф. // Журнал научн. и прикл. фотогр. и кинематогр. 1965. Т. 10. № 5. С. 397.

[7] Дьяконов А.Н., Завлин П.М. Полимеры в кинофотоматериалах. Л.: Химия, 1991. 240 с.

[8] Белоус В.М., Жуков С.А., Орловская Н.А. // Журнал научн. и прикл. фотогр. и кинематогр. 1982. Т. 27. № 3. С. 218.

[9] Жуков С.A. Автореф. канд. дис. Одесса, 1991.

[10] Sakuragi S., Kanzaki H. // Phys. Rev. Lett. 1977. V. 38. N 22. P. 1302.

[11] Денисова Н.В., Белоус В.М., Денисов И.Г., Деминов Р.Г. // Журнал научн. и прикл. фотогр. и кинематогр. 1989. Т. 34. № 3. C. 221.

[12] Денисова Н.В. Автореф. канд. дис. Казань, 1989.

[13] Белоус В.М., Ахмеров А.Ю., Жуков С.А., Орловская Н.А. // Журнал научн. и прикл. фотогр. и кинематогр. 2001. Т. 46. № 2. C. 19.

[14] Ляндо В.А., Ведерникова А.О., Логинова И.С., Ефимова Л.И., Мусина А.Н., Загирова Г.Г. // Журн. научн. и прикл. фотогр. и кинематогр. 1982. Т. 27. № 5. С. 364. 